\title{
Clinical response to calcium channel blockers in a hemodynamically unstable patient with reactive idiopathic pulmonary arterial hypertension
}

\author{
Grzegorz Kopec, Marcin Waligóra, Anna Tyrka, Monika Komar, Natasza Herman, Piotr Podolec
}

Department of Cardiac and Vascular Diseases, Jagiellonian University Medical College, John Paul II Hospital, Krakow, Poland

Submitted: 8 March 2015

Accepted: 18 March 2015

Arch Med Sci 2017; 13, 2: 504-506

DOI: https://doi.org/10.5114/aoms.2017.65230

Copyright @ 2017 Termedia \& Banach

Acute vasoreactivity testing is indicated in patients with idiopathic pulmonary arterial hypertension (IPAH) to identify subjects who will respond favorably to long-term treatment with calcium channel blockers (CCB) [1]. The result of the test determines the choice of treatment and predicts survival of the patient [2, 3]. It has been suggested that molecular etiology of IPAH is different in patients who respond or do not respond to CCB treatment [4]. In the current guidelines [1, 5] acute vasoreactivity testing is recommended in all patients with IPAH but treatment with CCB is advised only in those in World Health Organization functional class (WHO-FC) I-III. No guidelines are provided for patients with positive acute vasoreactivity testing who are in WHO-FC IV or who are hemodynamically unstable.

We present a case of a 29-year-old woman who was urgently admitted to the reference center for pulmonary hypertension from her local hospital due to rapidly progressing dyspnea and recurrent episodes of syncope. Her symptoms started 2 months before and progressed to WHO-FC IV at the time of admission. She presented with resting dyspnea, blood pressure of $90 / 60 \mathrm{~mm} \mathrm{Hg}$, a heart rate of 85 beats per minute and arterial blood saturation of $95 \%$. The electrocardiogram showed sinus rhythm with an incomplete right bundle branch block. Echocardiography showed typical signs of precapillary pulmonary hypertension with right ventricular dysfunction (Table I). N-terminal pro b-type natriuretic peptide (NT-proBNP) was significantly elevated (Table I). On the first day of hospitalization the patient experienced syncope after minimal exertion. It was followed by prolonged hypotension which required management with intravenous fluid and continuous infusion of dobutamine. After hemodynamic stabilization, still on dobutamine, she underwent further diagnostic tests according to the current guidelines [1]. She was HIV negative; pulmonary function tests and lung perfusion scans were normal. Abdominal USG and laboratory tests excluded liver disease. Physical examination and laboratory tests did not suggest a diagnosis of connective tissue disease. Echocardiography was negative for congenital heart disease. These results together with right heart catheterization (day 4) confirmed the diagnosis of IPAH (Table I) [6]. Acute pulmonary vasoreactivity (20 ppm of nitric oxide over $5 \mathrm{~min}$ ) was positive. Mean pulmonary artery pressure decreased from $49 \mathrm{~mm} \mathrm{Hg}$ to $26 \mathrm{~mm} \mathrm{Hg}$ without a change in the cardiac index $\left(2.1 \mathrm{l} / \mathrm{min} / \mathrm{m}^{2}\right)$. We started treatment with amlodipine

\author{
Corresponding author: \\ Grzegorz Kopec \\ Department of Cardiac \\ and Vascular Diseases \\ Jagiellonian University \\ Medical College \\ John Paul II Hospital \\ 80 Pradnicka St \\ 31-202 Krakow, Poland \\ Phone: +48 126143399 \\ E-mail: g.kopec@uj.edu.pl
}


Clinical response to calcium channel blockers in a hemodynamically unstable patient with reactive idiopathic pulmonary arterial hypertension

Table I. Functional and hemodynamic status of the patient at admission and at 3-month follow-up

\begin{tabular}{|c|c|c|}
\hline Parameter & Baseline & 3-month follow-up \\
\hline \multicolumn{3}{|l|}{ Functional status: } \\
\hline WHO-FC & IV & II \\
\hline $6 \mathrm{MWD}[\mathrm{m}]$ & $\begin{array}{c}0 \text { at admission; } \\
370 \text { m at discharge }\end{array}$ & 450 \\
\hline \multicolumn{3}{|l|}{ Echocardiography: } \\
\hline Proximal RVOT [mm] & 34 & 29 \\
\hline TAPSE $[\mathrm{mm}]$ & 14 & 17 \\
\hline $\operatorname{RAA}\left[\mathrm{cm}^{2}\right]$ & 24 & 17 \\
\hline PAd $[\mathrm{mm}]$ & 42 & 28 \\
\hline RVSP $[\mathrm{mm} \mathrm{Hg}]$ & 88 & 55 \\
\hline Pericardial fluid & Present & Absent \\
\hline NT-proBNP [pg/ml] & $3141^{*}$ & $132^{*}$ \\
\hline \multicolumn{3}{|l|}{ Right heart catheterization: } \\
\hline $\mathrm{PAP} \mathrm{s} / \mathrm{m} / \mathrm{d}[\mathrm{mm} \mathrm{Hg}]$ & $72 / 49 / 38$ & $53 / 29 / 18$ \\
\hline Mean RAP [mm Hg] & 1 & 1 \\
\hline $\mathrm{Cl}\left[\mathrm{l} / \mathrm{min} / \mathrm{m}^{2}\right]$ & 2.1 & 2.9 \\
\hline Mean PAWP [mm Hg] & 10 & 8 \\
\hline PVR [WU] & 10.2 & 3.9 \\
\hline SVR [WU] & 25.9 & 16.7 \\
\hline $\mathrm{SpO}_{2}$ in pulmonary artery [\%] & 66 & 72 \\
\hline Systemic pressure s/m/d [mm Hg] & $120 / 97 / 85$ & $111 / 89 / 78$ \\
\hline
\end{tabular}

$\mathrm{Cl}$ - cardiac index, PAd - pulmonary artery diameter, PAP - pulmonary artery pressure, PAWP - pulmonary artery wedge pressure, PVR pulmonary vascular resistance, RAA - right atrium area, RAP - right atrial pressure, RVOT - right ventricular outflow tract, RVSP - right ventricular systolic pressure, $\mathrm{SPO}_{2}$ - oxygen saturation, $\mathrm{s} / \mathrm{m} / \mathrm{d}$ - systolic/mean/diastolic, SVR - systemic vascular resistance, TAPSE tricuspid annular plane systolic excursion; * the upper reference limit is $125 \mathrm{pg} / \mathrm{ml}$.

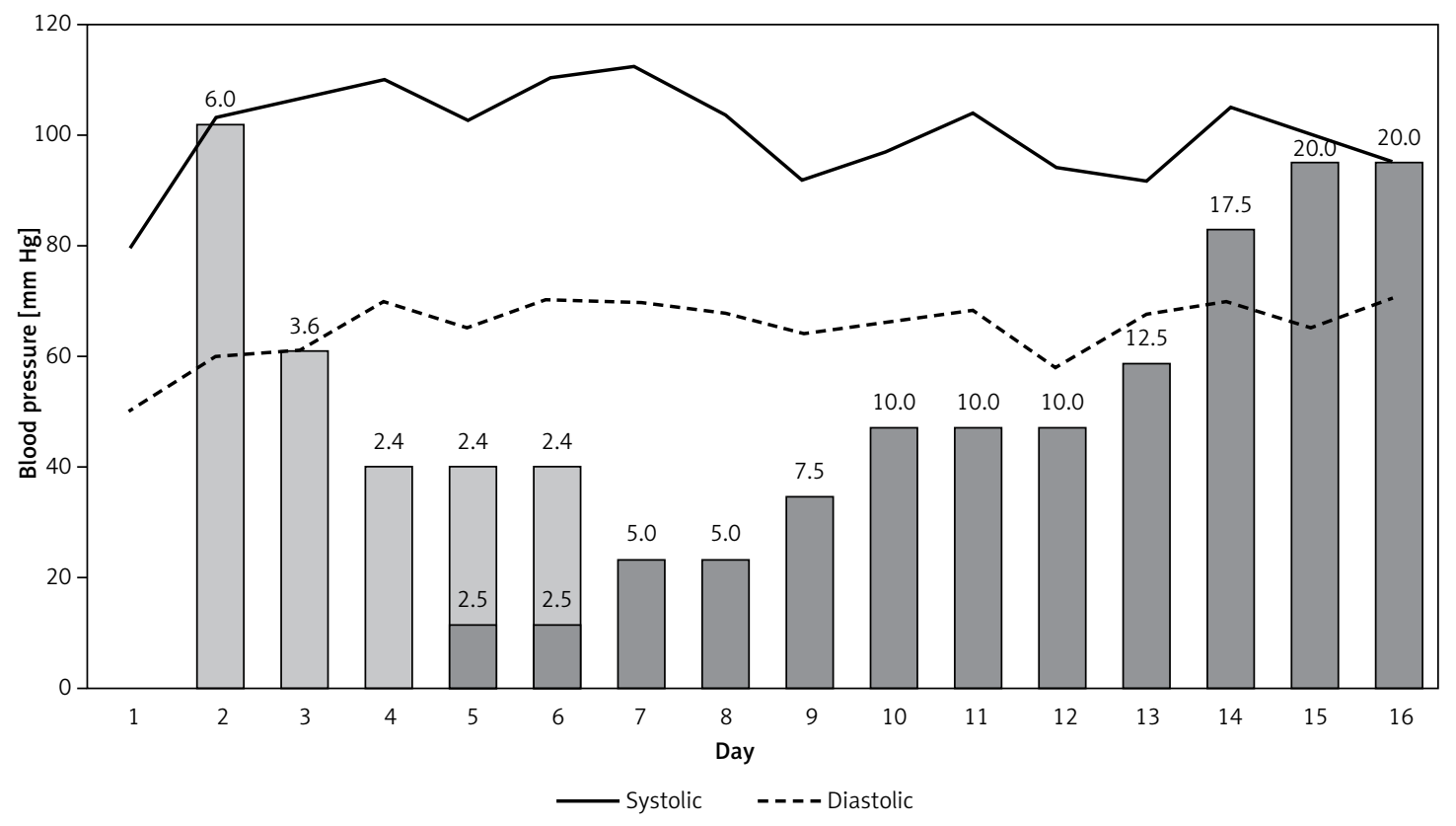

$\square$ Dose of dobutamine $[\mu \mathrm{g} / \mathrm{kg} / \mathrm{min}] \quad \square$ Dose of amlodipine [mg]

Figure 1. Monitoring of systemic arterial pressure. The pressure was stabilized on dobutamine infusion and then maintained despite starting treatment with amlodipine 
$2.5 \mathrm{mg}$ while continuing inotropic support. After

2 days we were able to stop dobutamine infusion (Figure 1). At discharge the dose of amlodipine was $20 \mathrm{mg}$, and the patient was in WHO-FC II with 6 min walk distance of $370 \mathrm{~m}$. The dose of amlodipine was increased in the outpatient clinic up to $40 \mathrm{mg}$ daily. Three months follow-up showed marked hemodynamic and functional improvement, as shown in Table I. At 12 months follow-up the patient was at WHO-FCI, with 6 min walking distance of $490 \mathrm{~m}$ and no episodes of syncope.

Observational studies showed a long-term benefit from CCB therapy in stable patients with vasoreactive IPAH at WHO-FC I-IV [3]. Our report is the first to present successful treatment with CCB of a hemodynamically compromised patient with vasoreactive IPAH. Based on this observation we suggest that in patients with vasoreactive IPAH an attempt of CCB therapy should be considered even when hemodynamic stabilization is dependent on inotropic support. The treatment should be closely monitored and prostacyclin therapy should be started in case of treatment failure with CCB $[1,7]$.

\section{Conflict of interest}

The authors declare no conflict of interest.

\section{References}

1. Galiè N, Hoeper MM, Humbert M, et al. Guidelines for the diagnosis and treatment of pulmonary hypertension. Eur Heart J 2009; 30: 2493-537.

2. Rich S, Kaufmann E, Levy PS. The effect of high doses of calcium-channel blockers on survival in primary pulmonary hypertension. N Engl J Med 1992; 327: 76-81.

3. Sitbon $\mathrm{O}$, Humbert $\mathrm{M}$, Jais $\mathrm{X}$, et al. Long-term response to calcium channel blockers in idiopathic pulmonary arterial hypertension. Circulation 2005; 111: 3105-11.

4. Hemnes AR, Trammell AW, Archer SL, et al. A peripheral blood signature of vasodilator-responsive pulmonary arterial hypertension. Circulation 2015; 131: 401-9.

5. McLaughlin VV, Gaine SP, Howard LS, et al. Treatment goals of pulmonary hypertension. J Am Coll Cardiol 2013; 62: D73-81.

6. Sinha N, Devabhaktuni S, Kadambi A, McClung JA, Aronow WS, Lehrman SG. Can echocardiographically estimated pulmonary arterial elastance be a non-invasive predictor of pulmonary vascular resistance? Arch Med Sci 2014; 29: 692-700.

7. Bergot E, Sitbon O, Cottin V, et al. Current epoprostenol use in patients with severe idiopathic, heritable or anorexigen-associated pulmonary arterial hypertension: data from the French pulmonary hypertension registry. Int J Cardiol 2014; 172: 561-7. 